\title{
EVIDENCIAÇÃO DAS ESTRATÉGIAS DE LEGITIMIDADE NOS RELATÓRIOS DA ADMINISTRAÇÃO DA EMPRESA VALE S/A
}

\section{LEGITIMACY STRATEGIES DISCLOSED IN THE MANAGEMENT REPORTS OF THE COMPANY VALE S/A}

\author{
Denise Rose Bracht Fank \\ PPGCCA/Unochapecó \\ E-mail: denisefank@unochapeco.edu.br \\ Rodney Wernke \\ E-mail: rodneywernke1@hotmail.com \\ Antônio Zanin \\ PPGCCA/Unochapecó \\ E-mail: zann@unochapeco.edu.br
}

\section{RESUMO}

A preocupação com a sustentabilidade contribuiu para o aparecimento de práticas empresariais que ficaram conhecidas como gestão ambiental e que visam reduzir riscos e impactos ambientais negativos. Para legitimar isso, as empresas buscam divulgar informações sociais nos relatórios anuais de administração, o que pode servir para mitigar a intervenção política, pois gestores podem decidir acerca da quantidade e da natureza da evidenciação social e ambiental que a empresa faz. Entre as formas de divulgação dessas práticas de sustentabilidade, diversas empresas têm priorizado os Relatórios da Administração (RA). Nesse sentido, esta pesquisa tem o objetivo de identificar as estratégias de legitimidade da tipologia de Suchman (1995) que a companhia de mineração Vale S. A. mencionou nos seus relatórios da administração no período de 2010 a 2016. Para atingir o objetivo proposto foi utilizada metodologia de cunho exploratória, com base numa análise documental e abordagem qualitativa. Foram analisados os Relatórios da Administração publicados pela companhia nos anos citados, centrando-se a atenção em relação aos critérios "ganho", "manutenção" e "reparação", sendo identificadas 1.647 menções relacionadas com a legitimidade. Constatouse que o critério "ganho" apresentou a maior quantidade de itens presentes nos relatórios dos sete anos abrangidos, com $51,67 \%$ das citações. Por outro lado, ao se considerar as estratégias de legitimidade geral, pragmática, moral e cognitiva, os resultados demonstram que a estratégia geral foi a mais citada, seguida pela cognitiva, pragmática e moral, respectivamente. Quanto às possíveis contribuições do estudo, considera-se que o aspecto mais relevante está ligado ao comparativo efetuado com estudos realizados em outras empresas (nacionais e estrangeiras), o que permite comparações nas formas de conduta de suas atividades relacionados à legitimidade.

Palavras-chave: Legitimidade; Tipologia; Relatórios de Administração.

\section{ABSTRACT}

Concerns about sustainability contributed to the emergence of business practices that became known as environmental management and aimed at reducing risks and negative environmental 
impacts. To legitimize this, companies seek to disclose social information in annual management reports, which can serve to mitigate political intervention, as managers can decide about the amount and nature of social and environmental disclosure that the company does. Among the ways of disclosing these sustainability practices, several companies have prioritized the Management Reports (AR). In this sense, this research aims to identify the legitimacy strategies of the typology of Suchman (1995) that the mining company Vale SA mentioned in its management reports from 2010 to 2016. To achieve the proposed objective an exploratory approach was used based on documentary analysis and qualitative approach. The Management Reports published by the company in the aforementioned years were analyzed, focusing on the criteria "gain", "maintenance" and "repair", and 1,647 mentions related to legitimacy were identified. It was found that the criterion "gain" presented the largest amount of items present in the reports of the seven years covered, with $51.67 \%$ of citations. On the other hand, when considering the strategies of general, pragmatic, moral and cognitive legitimacy, the results show that the general strategy was the most cited, followed by the cognitive, pragmatic and moral, respectively. Regarding the possible contributions of the study, it is considered that the most relevant aspect is related to the comparison made with studies conducted in other companies (domestic and foreign), which allows comparisons in the conduct of their activities related to legitimacy.

\section{Keywords: Legitimacy; Typology; Management Reports.}

\section{INTRODUÇÃO}

Nos últimos anos tem-se percebido no Brasil uma onda de conscientização acerca do meio ambiente e da sustentabilidade. Em relação à sustentabilidade, o foco principal se concentra em oferecer condições favoráveis de vida à população, de modo a conservar o meio ambiente e envolvendo a discussão de como explorar os recursos naturais e manter o crescimento econômico, com conservação do meio ambiente e melhoria na qualidade de vida da população, entre outros aspectos (Coronel, Lago, Lengler, \& Silva, 2007). Vilela Júnior e Demajorovic (2006, p. 14) corroboram esse posicionamento quando destacam que "no Brasil existe atualmente um movimento empresarial relacionado à crescente preocupação com as questões sociais e ambientais, bem como com a adoção de posturas éticas em suas atividades".

Nesse sentido, Rosa e Lunkes (2005) mencionam que a conscientização sobre a sustentabilidade contribuiu para o surgimento de práticas empresariais apelidadas de gestão ambiental, que têm em vista a mitigação dos riscos e impactos ambientais negativos. Ainda, para Gubiani, Soares e Beuren (2009) as organizações estão inseridas num ambiente que induz à necessidade de definir estratégias de ação, as quais exercem pressões que as influenciam com o propósito de garantir sua sobrevivência e sua legitimidade. Com isso, as empresas estão em busca dessa legitimidade por meio da divulgação de informações sociais nos relatórios anuais de administração com o intuito de evitar ou reduzir a intervenção política, de vez que os administradores podem decidir a quantidade e a natureza da evidenciação social e ambiental que a empresa apresenta.

A respeito disso, Watts e Zimmerman (1990) argumentam que um fator que pode explicar a evidenciação voluntária de informações sociais é o fato de que esta tem a capacidade de influenciar a visibilidade política da empresa, de forma a assegurar a possibilidade de não existirem restrições para a manutenção de contratos com órgãos governamentais. 
Essa legitimidade costuma ser evidenciada nos relatórios da administração, sendo que a Lei das Sociedades por Ações (Lei $n^{\circ}$ 6.404/76), alterada pela Lei $n^{\circ} 11.638 / 07$ e pelo Parecer de Orientação $n^{\circ} 15 / 87$ da Comissão de Valores Mobiliários (CVM) é quem ampara legalmente os relatórios contábeis a respeito no Brasil, flexibilizando seu conteúdo de modo que as companhias tenham a possibilidade de informar além do que está previsto na legislação.

Nesse contexto, Suchman (1995) propõe uma tipologia de estratégias de legitimidade que envolve quatro categorias: geral, pragmática, moral e cognitiva. Ainda que essas estratégias não versem diretamente sobre a evidenciação contábil, a referida tipologia pode ser utilizada na análise do conteúdo compulsório e voluntário dos relatórios que são publicados anualmente pelas companhias (Gubiani, Soares, \& Beuren, 2009).

A análise da legitimidade na empresa de mineração Vale S.A. decorre do custo político de suas decisões e ações que, objetivando a sua continuidade institucional e devido atuar num ramo de negócio com consideráveis índices de desastres ambientais. Além disso, a empresa em conjunto com a empresa BHP Billiton Brasil Ltda controla a empresa Samarco Mineração S.A., que teve o caso do rompimento da barragem de rejeito da Samarco, tragédia que ocorreu em Mariana, Minas Gerais em 2015, e desde então as empresas buscam mostrarse ao seu público que é correta e legitimada a atuar na sociedade, com o desenvolvimento de ações em benefício da sociedade

Destarte, neste estudo se pretende buscar resposta para a seguinte questão: quais as estratégias de legitimidade da tipologia de Suchman (1995) que a companhia de mineração Vale S. A. evidenciou nos seus relatórios da administração no período de 2010 a 2016? Para essa finalidade foi fixado como objetivo de estudo identificar as estratégias de legitimidade da tipologia de Suchman (1995) que a companhia de mineração Vale S. A. mencionou nos seus relatórios da administração no período de 2010 a 2016.

É pertinente mencionar que estudo com esse enfoque justifica-se porque a análise da legitimidade é relevante do ponto de vista das empresas pois estas são cada vez mais pressionadas pela sociedade a demonstrar que se preocupam com o meio ambiente e com o campo social, ao mesmo tempo que buscam a geração de riquezas para seus investidores (Suchman, 1995; O’Donovan, 2002; Farias, Andrade, Góes, \& Rabelo Filho, 2014; Suarez, Román, \& Román, 2014; Casagrande \& Lavarda, 2015).

Nesse sentido, do ponto de vista da teoria da legitimidade é interessante investigar sobre a tendência do comportamento das entidades diante da divulgação de informações socioambientais, o que pode contribuir para a ampliação do conhecimento sobre este campo de estudo ainda pouco explorado na literatura contábil brasileira (Lindblom, 1994; Suchman, 1995; Palazzo \& Scherer, 2006; Lunkes, Schnorrenberger, Souza, \& Rosa, 2012; Casagrande \& Lavarda, 2015).

\section{REFERENCIAL TEÓRICO}

No radar do institucionalismo das organizações, a legitimidade vem sendo referenciada como um conceito importante (Deephouse \& Suchman, 2008; Scott, 2001; Suchman, 1995). Nessa linha, Parsons (1956) e Pfeffer e Salancik (1978) mencionam que desde que as organizações fazem uso de recursos ambientais as suas atitudes são constantemente avaliadas pela sociedade para verificar se são apropriadas e se seus produtos e resultados são socialmente úteis, diante de alguns critérios legitimamente definidos. Diante do exposto, a legitimidade organizacional é considerada como uma consequência da interpretação das atitudes e toma como base a sua comparação com valores socialmente legítimos. 
Na concepção de Scott (2001) a legitimidade é um ativo intangível que não pode ser observado de forma direta, mas alguns autores elaboraram medidas indiretas na tentativa de tentar mensurar a legitimidade construindo modelos que atestam a legitimidade sociopolítica regulatória, a sociopolítica normativa e a cognitiva.

A teoria da legitimidade tem suas raízes no conceito de um contrato social entre a empresa e a sociedade, baseando-se na ideia de que, para continuar atuando de forma próspera, as empresas precisam agir conforme o que a sociedade identifica como comportamento socialmente aceitável. Para tanto, uma organização pode seguir três estratégias para desenvolver sua legitimidade: $(i)$ fazer uma adaptação dos seus resultados, métodos e objetivos para harmonizar com as percepções de legitimidade da sociedade; (ii) tentar alterar os valores da sociedade com o objetivo de moldá-la com as ações da empresa e (iii) transformar a visão da sociedade sobre a empresa, identificando valores da entidade que têm forte alicerce de legitimidade social (O'Donovan, 2002).

Quanto mais uma empresa evidenciar que, em conjunto com os resultados econômicos, está preocupada com a conservação e a preservação do meio social e ambiental, mas ela estará resguardando sua permanência e legitimidade na sociedade. Lima e Viegas (2002, p. 47) asseveram que "não se trata de a empresa ser, ou não, ecologicamente correta. A preocupação com a questão ambiental é ética e econômica, pois dela depende a permanência da empresa no mercado".

Cabe destacar que a teoria da legitimidade é derivada da teoria dos contratos porque, segundo Dias Filho (2007), começou a ser utilizada na área contábil principalmente em pesquisas que buscam explicações para a adoção de certos mecanismos de evidenciação. Essa teoria estabelece que existe um contrato entre as organizações e a sociedade, baseado num sistema de crenças e valores vigentes e sob essa perspectiva as organizações deveriam procurar estabelecer uma congruência entre as suas atividades e as expectativas da sociedade. Portanto, as empresas se esforçam para que sejam vistas como socialmente responsáveis para poder continuar extraindo do ambiente os recursos necessários para o cumprimento de seus objetivos.

No entender de Boff (2007), uma entidade que passa a fazer parte de um novo ambiente tem a opção de aceitar ou se adequar aos padrões já definidos e legitimados. Com isso, reduz o risco de rejeição pelas organizações e indivíduos ou estabelece seus próprios padrões, expressando-se de maneira indiferente aos padrões e regras já estabelecidos no ambiente.

Sancovschi e Silva (2006) citam que quando ocorrer uma ameaça presente ou potencial à legitimidade da empresa, decorrente de um evento negativo, os administradores podem tentar mudar a percepção dos que estão do lado de fora, com o objetivo de aumentar a congruência entre as atividades da organização e a expectativa da sociedade.

Ainda, a legitimidade é uma qualidade específica atribuída ao governo (ou aos sistemas de governança) que resulta na obrigação do real cumprimento das normas, regras e decisões políticas. Dessa forma, a legitimidade dos atos políticos promove o exercício do poder, uma vez que reflete de maneira positiva na confiança que a sociedade tem nos gestores (Steffek, 2009).

\subsection{Legitimidade com base na tipologia de Suchman (1995)}

Para Suchman (1995, p. 574), a legitimidade pode ser definida como "a percepção generalizada de que determinadas ações são autênticas, adequadas, ou necessárias em um sistema de normas, valores e crenças socialmente construídos". Comenta, ainda, que um dos 
enfoques mais antigos sobre legitimidade organizacional foi apresentado por Maurer (1971), o qual elucidou que a legitimação é o processo pelo qual uma organização, em determinado momento, justifica ao sistema onde atua o direito de existir.

Com o fito de interpretar e explicar fenômenos organizacionais, Suchman (1995) identificou estratégias com o intuito de ganhar, manter ou recuperar a legitimidade organizacional. Nessa direção, as tipologias de legitimidade propostas pelo referido autor são quatro: legitimidade geral, pragmática, moral e cognitiva, a fim de servirem como parâmetro na identificação da legitimidade nos relatórios divulgados pelas empresas. Nesse caso, cada estratégia é constituída por valores e definições, adotando diferentes dinâmicas e formas Comportamentais, conforme delineado na Tabela 1. 
Tabela 1

Estratégias de legitimidade de Suchman

\begin{tabular}{|c|c|c|c|}
\hline \multirow[t]{2}{*}{ Categorias } & \multicolumn{3}{|c|}{ Estratégias para a Legitimação } \\
\hline & Ganho & Manutenção & Reparação \\
\hline \multirow[t]{3}{*}{ Geral } & Adaptar-se ao ambiente & Perceber mudanças & Normalizar \\
\hline & Selecionar o ambiente & $\begin{array}{c}\text { Favorecer as realizações. } \\
\text { Monitorar as operações } \\
\text { Comunicar-se habilmente } \\
\text { Estocar legitimidade }\end{array}$ & Reestruturar \\
\hline & Manipular o ambiente & & Resolver com tranquilidade \\
\hline \multirow[t]{3}{*}{ Pragmática } & $\begin{array}{l}\text { Adaptar-se às exigências } \\
\text { Responder as necessidades } \\
\text { Cooptar integrantes } \\
\text { Construir reputação }\end{array}$ & $\begin{array}{c}\text { Monitorar interesses } \\
\text { Consultar a opinião de líderes }\end{array}$ & Rejeitar \\
\hline & $\begin{array}{c}\text { Selecionar mercados } \\
\text { Localizar públicos amistosos } \\
\text { Recrutar cooperadores } \\
\text { amistosos }\end{array}$ & $\begin{array}{c}\text { Favorecer trocas } \\
\text { Monitorar a confiabilidade. } \\
\text { Comunicar-se honestamente. } \\
\text { Estocar confiança }\end{array}$ & Criar monitores \\
\hline & $\begin{array}{c}\text { Anunciar } \\
\text { Anunciar o produto } \\
\text { Anunciar a imagem }\end{array}$ & & \\
\hline \multirow[t]{3}{*}{ Moral } & $\begin{array}{c}\text { Adaptar-se aos ideais. } \\
\text { Produzir resultados adequados. } \\
\text { Incorporar-se a instituções. } \\
\text { Oferecer demonstrações } \\
\text { simbólicas } \\
\end{array}$ & $\begin{array}{c}\text { Monitorar a ética. } \\
\text { Consultar as categorias } \\
\text { profissionais } \\
\end{array}$ & $\begin{array}{l}\text { Desculpar } \\
\text { Justificar }\end{array}$ \\
\hline & $\begin{array}{l}\text { Selecionar o dominio. } \\
\text { Definir as metas. }\end{array}$ & $\begin{array}{l}\text { Favorecer a boa conduta. } \\
\text { Monitorar a responsabilidade. } \\
\text { Comunicar-se oficialmente. } \\
\text { Estocar opiniōes favoráveis }\end{array}$ & $\begin{array}{l}\text { Desassociar. } \\
\text { Substituir pessoal. } \\
\text { Rever as práticas. } \\
\text { Reconfigurar }\end{array}$ \\
\hline & $\begin{array}{c}\text { Persuadir. } \\
\text { Demonstrar sucesso. } \\
\text { Fazer proselitismo } \\
\text { (trazer adeptos) }\end{array}$ & & \\
\hline \multirow[t]{3}{*}{ Cognitiva } & $\begin{array}{c}\text { Adaptar-se aos modelos. } \\
\text { Reproduzir normas } \\
\text { Formalizar as operações } \\
\text { Profissionalizar as operações }\end{array}$ & $\begin{array}{l}\text { Monitorar perspectivas } \\
\text { Consultar aqueles que têm } \\
\text { dúvidas }\end{array}$ & Explicar \\
\hline & $\begin{array}{l}\text { Selecionar rótulos } \\
\text { Buscar certificação }\end{array}$ & $\begin{array}{l}\text { Proteger hipóteses } \\
\text { Visar clareza } \\
\text { Falar pontualmente } \\
\text { Estocar conexões } \\
\end{array}$ & \\
\hline & $\begin{array}{c}\text { Institucionalizar } \\
\text { Persistir } \\
\text { Popularizar novos modelos } \\
\text { Padronizar novos modelos }\end{array}$ & & \\
\hline
\end{tabular}

Fonte: adaptado de Suchman (1995)

A legitimidade geral tem como tônica a percepção da organização em relação ao ambiente em que atua, pois as empresas necessitam se cercar de mecanismos de controle, que na visão de Suchman (1995) têm o objetivo de monitorar o ambiente em que atuam, a fim de compreender as mudanças que ocorrem ao seu redor. Por seu turno, Gubiani, Soares e Beuren (2009) aduzem que as empresas devem adotar medidas pré-estabelecidas em harmonia com sua missão diante de quaisquer fatos que possam originar perdas no seu desempenho e 
aceitação, pois a legitimidade geral serve de base para a instituição e aplicação das demais estratégias.

Quanto à legitimidade pragmática, Gubiani, Soares e Beuren (2009, p. 4) asseveram que esta "tem como foco os efeitos sobre a troca da influência dos atos da entidade". A legitimidade pragmática, para Suchman (1995), se resume em uma espécie de apoio recíproco para que seja implementada uma política com base na expectativa que atenda um determinado conjunto de elementos que sirvam a interesses comuns. Em outras palavras, refere-se ao caráter definido pelas organizações em se comportar dentro dos parâmetros estabelecidos por alguma esfera reguladora. Outra forma de estabelecer a legitimidade pragmática está relacionada à influência dos atos da entidade e, nesse caso, o público nutre o apoio à organização, não fundamentalmente porque acredita que esta ofereça benefícios diretos, mas por perceber as ações da organização como resposta aos seus anseios. O caráter mais importante da legitimidade pragmática é concretizado pela necessidade da organização em conseguir informações sobre a percepção do seu público-alvo relacionadas às suas atividades, visto que com isso o seu público-alvo também passa a compreender de forma ampla todas as suas relações institucionais (como as políticas e os aspectos econômicos e sociais).

No que concerne à legitimidade cognitiva, Suchman (1995) alega que esta pode abranger tanto o apoio afirmativo (ativo) para uma entidade (com fundamento em conceitos culturais) como uma aceitação passiva. A legitimidade cognitiva é proveniente de uma herança cultural que adota uma entidade como certa no seu ambiente, sem que seja realizado qualquer ajuizamento peculiar. Para o autor, a legitimidade pode submeter um padrão tanto positivo, negativo ou nenhum padrão de avaliação. Entretanto, na concepção de Scott (2001) a legitimidade cognitiva provém das crenças e pressupostos que fornecem um modelo de hábito diário, complementado com conhecimento especializado e explícito, codificado como um sistema de crenças e divulgado por vários profissionais.

Desse modo, Fank e Beuren (2010) observaram os resultados dos itens da legitimidade cognitiva da empresa Petrobrás nos anos 2000 a 2009 e dessumiram que "popularizar novos modelos" e "padronizar novos modelos" se destacaram dos demais, sendo seguidos por "reproduzir normas", "formalizar as operações", "profissionalizar as operações" e "buscar certificação perante órgãos reguladores". Assim, demonstrou-se uma preocupação da empresa para desenvolver projetos de pesquisas, tendo como finalidade a implantação de inovações na forma de administrar suas atividades e buscar a excelência nas suas operações, atenuando a probabilidade de ocorrerem fracassos no processo.

No que concerne à legitimidade moral, esta modalidade está baseada numa avaliação do comportamento ético da organização, em que alguma atividade possui a característica de "se fazer a coisa certa" para promover o bem-estar da sociedade, conforme o sistema de valores construídos socialmente. Assim, para conseguir legitimidade perante os stakeholders, as organizações frequentemente reivindicam a sua propriedade moral por meio de ações simbólicas que ficam visíveis, muitas vezes, na percepção da sociedade como um todo. Além disso, a legitimidade moral reflete uma lógica pró-social que se fundamenta no próprio interesse da entidade. Portanto, esse tipo de legitimidade pode adotar determinadas formas ("avaliação de resultados e consequências", "avaliação das técnicas e procedimentos" e "avaliação das categorias e das estruturas") na medida em que são avaliados os diferentes aspectos da performance da entidade. Com isso, a legitimidade moral pode ser segregada em quatro tipos: legitimidade dos resultados e/ou consequências, legitimidade processual, legitimidade estrutural e legitimidade pessoal (Suchman, 1995).

Acerca desse tipo de legitimidade, Fank e Beuren (2010) analisaram os Relatórios da Administração da Petrobrás e constataram que a opção "demonstrar sucesso" tem a maior quantidade de citações, seguido por "produzir resultados adequados", "oferecer 
demonstrações simbólicas" e "definir as metas". Desse modo, percebe-se que tal empresa buscava na sua atividade resultados que possibilitassem aliar os procedimentos internos ao código de ética e de responsabilidade social para evidenciar seu nível de sucesso na promoção do bem-estar da sociedade.

\subsection{Estudos anteriores}

A respeito da legitimidade, diversas pesquisas foram publicadas nos últimos anos, conforme destacado a seguir.

Beuren, Hein e Boff (2006) averiguaram a relação existente entre as estratégias de legitimidade organizacional propostas por Lindblom (1994) que foram evidenciadas no relatório da administração de empresas familiares brasileiras no período de 1997 a 2006 . Os resultados mostraram que as entidades estudadas empregaram mais a segunda estratégia ("mudar a percepção do público pertinente sobre seu atual desempenho e atividades sem ter que mudar seu comportamento atual") e a terceira estratégia de legitimidade organizacional ("manipular a percepção do público pertinente desviando a atenção sobre um assunto que chama atenção para outro assunto relacionado ou mesmo, destacando realizações sociais passadas no lugar de informá-los e educá-los") para evidenciar aspectos ambientais e sociais de suas atividades. Das treze empresas familiares analisadas, seis passaram pelo processo de transição para outra geração familiar e/ou administração contratada. Relacionando as gerações familiares gestoras com as estratégias de legitimidade organizacional, verificou-se por meio do coeficiente " $\gamma$ " (que significa o grau de associação entre as estratégias de legitimidade ambiental, estratégias de legitimidade social e as gerações familiares) que a peculiaridade de administração familiar não interferiu na evidenciação ambiental e social no período analisado.

No intuito de identificar as estratégias de legitimidade da tipologia de Suchman (1995) deslindadas nos relatórios da administração da Petrobras no período entre 2000-2009, Fank e Beuren (2010) identificaram que: $(i)$ em relação à legitimidade geral, sobressaíram os critérios da manutenção; (ii) na legitimidade pragmática os procedimentos de anunciar a imagem e construir reputação se destacaram; (iii) em relação à legitimidade moral, houve destaque em demonstrar sucesso e definir metas e (iv) na legitimidade cognitiva destacaram-se as iniciativas de popularizar novos modelos, padronizar novos modelos, reproduzir normas, formalizar as operações, profissionalizar as operações e buscar certificação.

Lunkes et al. (2012) visaram identificar e analisar a legitimidade sociopolítica e cognitiva da controladoria no Brasil. Os resultados do estudo demonstraram que a controladoria, no âmbito brasileiro, apresenta legitimidade sociopolítica, ou seja, possui organismos e normas próprias. Contudo, ainda tem necessidade de melhorar os níveis de organização e desenvolvimento nos moldes do que ocorre nos Estados Unidos e na Alemanha. Em relação à legitimidade cognitiva, constataram que esta modalidade cresceu na publicação de livros e manuais, enquanto que a disciplina de controladoria está presente na maioria dos cursos de Ciências Contábeis e proporciona oportunidades de aperfeiçoamento no que se refere a publicações em periódicos.

Farias et al. (2014) objetivaram identificar as estratégias de legitimidade da tipologia de Suchman (1995) evidenciadas pela empresa Brasken. Identificaram que tal companhia adotou o compromisso de promover o desenvolvimento sustentável e reduzir as emissões de gases do efeito estufa (GEE) e vem adotando estratégias ambientais corporativas para seguilo. No que tange às estratégias de legitimidade foi identificada a ênfase à crescente legitimidade da empresa perante os stakeholders, o que caracteriza uma predominância da tipologia pragmática, com metade das evidenciações detectadas. Ainda, foi constatado que a 
empresa está se adaptando aos padrões de uma economia de baixo carbono no intuito de assegurar a sustentabilidade dos seus negócios.

Por sua vez, Lunkes et al. (2014) priorizaram a identificação e análise das características da legitimidade cognitiva da disciplina de planejamento tributário no Brasil. O trabalho abrangeu publicações em periódicos diretamente vinculados à área contábil e inclusos no Qualis da CAPES. Os resultados oriundos demonstram que existe legitimidade cognitiva do planejamento tributário relacionado aos livros e manuais em termos desta disciplina acadêmica. Contudo, defendem que no que concerne à legitimidade cognitiva nas publicações em revistas científicas e congressos há potencial e oportunidade para crescimento a respeito.

Casagrande e Lavarda (2015) objetivaram analisar as convergências teóricas entre a governança corporativa e a sustentabilidade, tendo como sustentação a teoria institucional. Na análise dos resultados observaram que a governança corporativa ganha alta prioridade na agenda dos formuladores de políticas organizacionais, investidores e acadêmicos, demonstrando que a ligação desta temática com a busca por legitimidade e a sustentabilidade revela-se um campo profícuo para a produção de pesquisas acadêmicas.

Parente, Barbosa e Gomes (2016) analisaram o papel das plataformas online, em particular sob a forma de websites, na afirmação de uma estratégia de comunicação externa das OTS (Organizações do Terceiro Setor). Na análise dos resultados sobre legitimidade pragmática apuraram que há maior investimento entre 2013 e 2016 (mesmo que ainda reduzido), indicando uma crescente preocupação com as relações externas e de oportunidades de financiamento. Em relação à legitimidade moral não verificaram diferenças nos indicadores, enquanto que a legitimidade cognitiva foi a dimensão que apresentou a evolução mais surpreendente porque registrou queda significativa nas suas duas subdimensões (o que denuncia uma falta de sustentabilidade e coesão na utilização dos websites). na Tabela 2.

$\mathrm{O}$ assunto legitimidade também vem sendo pesquisado no exterior, conforme exposto

Tabela 2

Estudos internacionais sobre legitimidade

\begin{tabular}{|c|c|}
\hline Autores & Objetivo \\
\hline $\begin{array}{c}\text { Lindblom } \\
(1994)\end{array}$ & Discute a legitimidade organizacional e como ocorre o processo de legitimação. \\
\hline $\begin{array}{l}\text { O’Donovan } \\
\text { (2002) }\end{array}$ & $\begin{array}{l}\text { Visa ampliar a capacidade de aplicabilidade e o poder preditivo da teoria da legitimidade. Para } \\
\text { tanto, investiga em que medida as divulgações de relatórios anuais estão inter-relacionadas com as } \\
\text { tentativas de obter, manter e reparar a legitimidade e escolher táticas de legitimação. }\end{array}$ \\
\hline $\begin{array}{l}\text { Deephouse } \\
\text { e Carter } \\
(2005)\end{array}$ & $\begin{array}{l}\text { Examinar a legitimidade e a reputação organizacional nas dimensões financeira, regulamentar e } \\
\text { pública em bancos comerciais dos EUA. }\end{array}$ \\
\hline $\begin{array}{l}\text { Palazzo e } \\
\text { Scherer } \\
(2006)\end{array}$ & Objetiva propor um fundamento político para a discussão sobre a legitimidade corporativa. \\
\hline $\begin{array}{l}\text { Suarez, } \\
\text { Román e } \\
\text { Román } \\
(2014)\end{array}$ & $\begin{array}{l}\text { Medir a relação entre a legitimidade cognitiva, acesso aos recursos e resultados organizacionais em } \\
\text { seis universidades públicas espanholas }\end{array}$ \\
\hline $\begin{array}{l}\text { Akerlof } \\
(2017)\end{array}$ & $\begin{array}{c}\text { Analisa se a legitimidade limitada dos líderes desempenha um papel importante no comportamento } \\
\text { organizacional e na estrutura organizacional }\end{array}$ \\
\hline
\end{tabular}


Fisher,

Kotha e

Lahiri

(2016)

Investigou como a identidade organizacional de um novo empreendimento deve se adaptar para atender às expectativas dos provedores de recursos críticos em cada estágio do seu ciclo de vida organizacional.

Fonte: elaborada pelos autores.

\section{PROCEDIMENTOS METODOLÓGICOS}

Esta pesquisa classifica-se como exploratória, com base numa análise documental e com abordagem qualitativa. Acerca da característica inicial, conforme Gil (1999), a pesquisa exploratória é desenvolvida com o objetivo de confirmar uma visão geral sobre um determinado fato. Quanto à abordagem, considera-se como qualitativa porque buscou-se identificar se a empresa analisada nesse estudo evidencia as estratégias de legitimidade definidas por Suchman (1995). Para Richardson (1989, p. 38), a pesquisa qualitativa "difere em princípio, da quantitativa, à medida que não emprega um instrumento estatístico como base do processo de análise". Em relação aos procedimentos a pesquisa classifica-se como documental, pois foi realizada a análise utilizando-se os Relatórios da Administração como fonte de dados. Para Silva (2003, p. 61) a pesquisa documental "difere da pesquisa bibliográfica por utilizar material que ainda não recebeu tratamento analítico ou que pode ser reelaborado e suas fontes são muito diversificadas ou dispersas".

Nessa direção, foram analisados os dados da companhia de mineração Vale S. A. compreendendo o período de 2010 a 2016. Para analisar o período abrangido pela pesquisa foram examinados os Relatórios da Administração coletados no site da B3 (www.b3.com.br). Destarte, a técnica de análise utilizada na pesquisa compreende a análise de conteúdo dos Relatórios da Administração, sendo que esta técnica analítica prevê estudo de interpretação de textos para compreender a construção de resultados (Bardin, 1977).

O parâmetro para análise adotado fundamentou-se em cada um dos itens que compõem as estratégias de Suchman (1995). Para tanto, foi elaborada uma planilha com as categorias e subcategorias contidas na proposta do referido pesquisador considerando-se as estratégias de legitimação geral, pragmática, moral e cognitiva. Em cada uma delas foi registrada no respectivo ano a frase ou parágrafo identificado na análise de conteúdo dos Relatórios da Administração da empresa em tela. Assim, todos os parágrafos foram lidos para identificar as categorias e subcategorias citadas, sendo que cada parágrafo foi considerado somente uma vez para fins de classificação do seu conteúdo. Após essa análise de conteúdo os dados coletados foram quantificados e organizados em tabelas, conforme proposto por Suchman (1995) para demonstrar o total de itens evidenciados nos relatórios abrangidos.

\section{APRESENTAÇ̃̃O E ANÁLISE DOS RESULTADOS}

A Vale S. A. é uma das maiores empresas de minério do mundo e trabalha para transformar os recursos naturais extraídos em riqueza. Tem como compromisso gerar prosperidade respeitando as pessoas e o meio ambiente, sendo uma empresa que acredita em um mundo mais sustentável e sempre está em busca de cuidado e respeito pelo planeta (Vale S. A., 2017).

Esta é uma companhia privada, de capital aberto, com sede no Brasil e presente em cerca de 30 países. Como uma das maiores mineradoras do mundo, a Vale S. A. é um dos líderes na extração de minério de ferro, pelotas e níquel. A empresa também produz manganês, ferroligas, carvão, cobre, ouro, prata, cobalto e fertilizantes. Além disso, atua nas áreas de siderurgia, logística e energia (Vale S.A., 2017). 
Quanto à política de sustentabilidade, a Vale entende que o seu desenvolvimento sustentável é adquirido quando seus negócios geram valor para os acionistas e as partes interessadas, com apoio ao fortalecimento social, mantendo e melhorando a qualidade da saúde e segurança dos trabalhadores e das comunidades vizinhas. Também mantém a responsabilidade ambiental e o desenvolvimento sócio econômico das regiões onde atua através de uma gestão consciente e responsável, com ações empresariais espontâneas e de parcerias intersetoriais, além de trabalhar com ética e transparência (Vale S.A., 2017).

\subsection{Estratégias para legitimidade geral}

Levando em consideração as menções às estratégias de Suchman (1995) relacionadas com legitimidade geral, pragmática, moral e cognitiva encontradas nos relatórios da administração da empresa pesquisada (entre 2010 e 2016) foi elaborada a Tabela 3.

Tabela 3

Estratégias para legitimidade geral

\begin{tabular}{|c|c|c|c|c|c|c|c|c|c|c|}
\hline & Estratégias p & a a Legitimação & 2010 & 2011 & 2012 & 2013 & 2014 & 2015 & 2016 & Total \\
\hline & & Adaptar-se ao ambiente & 12 & 18 & 6 & 6 & 2 & 6 & 2 & 52 \\
\hline & Ganho & Selecionar o ambiente & 8 & 8 & 2 & 0 & 0 & 0 & 2 & 20 \\
\hline & & Manipular o ambiente & 14 & 3 & 0 & 0 & 0 & 12 & 6 & 35 \\
\hline & & Perceber mudanças & 17 & 24 & 4 & 7 & 1 & 18 & 2 & 73 \\
\hline & Manutenção & Monitorar as operações & 17 & 19 & 8 & 3 & 2 & 14 & 4 & 67 \\
\hline $\bar{\pi}$ & & Comunicar-se habilmente & 25 & 16 & 9 & 6 & 9 & 15 & 14 & 94 \\
\hline$\ddot{~}$ & & Estocar legitimidade & 26 & 25 & 15 & 15 & 8 & 10 & 6 & 105 \\
\hline & & Normalizar & 4 & 6 & 2 & 1 & 0 & 2 & 0 & 15 \\
\hline & Reparação & Reestruturar & 1 & 10 & 3 & 0 & 0 & 11 & 4 & 29 \\
\hline & & Resolver com tranquilidade & 0 & 3 & 0 & 0 & 2 & 3 & 3 & 11 \\
\hline
\end{tabular}

Fonte: elaborada pelos autores.

Em relação aos itens da legitimidade geral nota-se que predominou o critério "manutenção", demonstrando que a companhia de mineração Vale S. A. está percebendo as mudanças no cenário, monitorando as suas operações e, a partir disso, comunicando-se habilmente com vistas a estocar legitimidade. Nesse aspecto, os resultados assemelham-se ao estudo de Fank e Beuren (2010) que objetivaram identificar as estratégias de legitimidade da tipologia de Suchman (1995) nos relatórios da administração da Petrobrás, onde identificaram que em relação à legitimidade geral sobressaiu-se também o critério da "manutenção".

Dentro do grupo de itens relacionados com a manutenção propostos por Suchmann (1995), apurou-se que "estocar legitimidade" destacou-se na análise dos relatórios realizada, seguido de "comunicar-se habilmente". No que tange ao período analisado, percebe-se que em 2010 houve maior quantidade de vezes que itens de manutenção foram detectados nos relatórios. Provavelmente isso se deve ao fato de que nesse ano tornou-se obrigatório para as empresas com capital aberto a implantação das normas internacionais de contabilidade (também conhecidas como IFRS) e a empresa descreveu esse processo em suas peças contábeis.

Percebeu-se também que nos anos de 2015 e 2016 a companhia apresentou itens relacionados a "ganho", "manutenção" e "reparação", sendo esse fato oriundo da ruptura da barragem de rejeitos da empresa Samarco, do qual as empresas Vale e BHP Biliton Brasil Ltda. são os principais acionistas. Em relação a essa ruptura, a Vale evidenciou no Relatório de Administração de 2015 o que considera que efetivamente ocorreu: 
Em 5 de novembro de 2015, uma das barragens da Samarco (Fundão) colapsou inesperadamente, lançando $32 \mathrm{Mm} 3$ de rejeitos arenosos e atingindo várias comunidades, incluindo a comunidade do distrito de Bento Rodrigues, onde viviam cerca de 600 pessoas. A ruptura da barragem resultou em 17 fatalidades, com duas pessoas ainda desaparecidas, e causou extenso dano às propriedades e ao meio ambiente das regiões afetadas nos Estados de Minas Gerais e Espírito Santo (RA Vale, 2015, p. 10)

No relatório de administração a empresa relatou, ainda, mais fatos ocorridos e as ações que estavam ou estão sendo feitas para reparar os dados causados pela ruptura.

Assim, em relação à legitimidade geral, no seu relatório de administração de 2015 evidenciou que "além das ações civis, a Samarco tem monitorado a região afetada e realizado trabalhos de emergência para conter movimentos adicionais de rejeitos, reforçando as estruturas das barragens para garantir a segurança da região" (RA - Vale, 2015, p. 10). Este trecho, então, evidencia que a empresa está buscando adaptar-se ao ambiente, percebeu as mudanças e está monitorando as operações, objetivando estocar legitimidade e manipular o ambiente, para que esse acontecimento não prejudique as suas demais atividades.

\subsection{Estratégias para legitimidade pragmática}

Em relação à legitimidade pragmática, Suchman (1995) menciona que se refere ao caráter definido pelas organizações em se comportar dentro dos parâmetros estabelecidos por alguma esfera reguladora, sendo que está relacionada à influência dos atos da entidade onde o público nutre o apoio à organização. Para o citado autor, o fator mais importante para a empresa quanto à legitimidade pragmática é de que esta consiga informações sobre a percepção do seu público-alvo relacionadas às suas atividades, pois nessa percepção seu público-alvo também passa a compreender de forma ampla todas as suas relações institucionais da companhia.

Sobre o assunto, a Tabela 4 demonstra a frequência que os itens da legitimidade pragmática foram evidenciados no relatório de administração da Vale S. A. no período de 2010 a 2016.

Tabela 4

Estratégias para legitimidade pragmática

\begin{tabular}{|c|c|c|c|c|c|c|c|c|c|c|}
\hline \multicolumn{3}{|c|}{ Estratégias para a Legitimação } & 2010 & 2011 & 2012 & 2013 & 2014 & 2015 & 2016 & Total \\
\hline \multirow{14}{*}{ 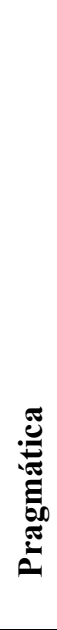 } & & Responder às necessidades & 8 & 14 & 2 & 0 & 0 & 19 & 4 & 47 \\
\hline & Ganho & Cooptar integrantes & 1 & 6 & 1 & 2 & 2 & 3 & 2 & 17 \\
\hline & & Construir reputação & 18 & 11 & 5 & 6 & 10 & 22 & 25 & 97 \\
\hline & & Localizar públicos amistosos & 4 & 5 & 2 & 0 & 0 & 2 & 0 & 13 \\
\hline & & Recrutar cooperadores amistosos & 5 & 1 & 1 & 1 & 2 & 0 & 1 & 11 \\
\hline & & Anunciar o produto & 11 & 12 & 8 & 3 & 2 & 3 & 5 & 44 \\
\hline & & Anunciar a imagem & 22 & 15 & 10 & 7 & 6 & 12 & 22 & 94 \\
\hline & & Monitorar interesses & 0 & 0 & 0 & 0 & 0 & 1 & 0 & 1 \\
\hline & & Consultar a opinião de líderes & 2 & 0 & 0 & 0 & 0 & 2 & 0 & 4 \\
\hline & Manutenção & Monitorar a confiabilidade & 4 & 1 & 0 & 0 & 0 & 0 & 1 & 6 \\
\hline & & Comunicar-se honestamente & 6 & 1 & 0 & 0 & 1 & 4 & 7 & 19 \\
\hline & & Estocar confiança & 21 & 14 & 4 & 2 & 2 & 1 & 4 & 48 \\
\hline & & Rejeitar & 0 & 0 & 0 & 0 & 0 & 0 & 0 & $\mathbf{0}$ \\
\hline & Reparação & Criar monitores & 0 & 1 & 1 & 1 & 0 & 2 & 0 & 5 \\
\hline
\end{tabular}

Fonte: elaborada pelos autores. 
A avaliação da Tabela 4 quanto aos itens da legitimidade pragmática permite concluir que predominou o critério "ganho", demonstrando que a empresa buscou a percepção da sociedade sobre ela, sendo que dos itens avaliados predominaram "construir reputação" e "anunciar a imagem", com 97 e 94 evidenciações, respectivamente. Esses resultados coadunam-se com Fank e Beuren (2010), de vez que na legitimidade pragmática os mesmos procedimentos de "anunciar a imagem" e "construir reputação" se destacaram nos relatórios de administração da Petrobrás.

Por outro lado, em relação à predominância do "ganho", dessumiu-se que a Vale busca responder às necessidades da sociedade e dos seus acionistas, objetivando que todas as partes possam ser cooperadores amistosos e, com isso, a sua imagem seja positiva e o seu produto tenha aceitação no mercado.

No que se refere à legitimidade pragmática, um trecho extraído do relatório de administração de 2015 mostra o que a empresa estava fazendo em relação à ruptura da barragem da Samarco:

\footnotetext{
Imediatamente após a ruptura da barragem de rejeitos, junto com a Defesa Civil, o Corpo de Bombeiros, a Polícia Militar e outras autoridades, a Samarco providenciou os primeiros socorros, comida, água, estadia, assistência social e suporte financeiro para centenas de famílias e indivíduos afetados. Até o presente momento, a Samarco: (a) finalizou a recuperação de todas as sete pontes impactadas pela ruptura da barragem; (b) acomodou todas as 369 famílias que perderam suas casas; (c) distribuiu 2.907 cartões de suporte financeiro para os residentes das cidades afetadas ( $75 \%$ do total das famílias afetadas); (d) providenciou atendimento psicossocial para 1.185 famílias; (e) distribuiu 553 milhões de litros de água potável e 59 milhões de litros de água mineral. Tanto a Vale quanto a BHP Billiton, acionistas da Samarco, têm se envolvido ativamente no suporte à Samarco durante esta crise (RA - Vale, 2015, p. 10).
}

No texto mencionado nota-se que a Vale está respondendo às necessidades das pessoas envolvidas ocasionadas pela situação do rompimento da barragem e se juntou a cooperadores amistosos para realizar as ações necessárias, objetivando melhorar sua reputação.

Ainda, em relação às ações quanto à ruptura da barragem da Samarco, no relatório de administração de 2016 a companhia mencionou que "desde o acidente com a barragem da Samarco em novembro de 2015, a Vale tem apoiado a Samarco nos esforços de reparação e mitigação dos danos, suportando os programas realizados pela Fundação Renova e contribuído para a manutenção e preservação dos ativos da Samarco" (RA - Vale, 2016, p. 4). Dessa forma, identifica-se uma preocupação da empresa em comunicar-se honestamente, estocando confiança, anunciando sua imagem e construindo sua reputação.

\subsection{Estratégias para legitimidade moral}

Suchman (1995) defende que a legitimidade moral está alicerçada na avaliação do comportamento ético da empresa, tendo a característica de fazer a coisa certa, objetivando o bem da sociedade. Então, para atingir a legitimidade moral, a empresa deve promover ações ou projetos que promovam o bem-estar e que fiquem visíveis na percepção da sociedade.

Acerca disso, a Tabela 5 demonstra a frequência com que os itens da legitimidade moral foram detectados no relatório de administração da Vale no período analisado. 
Tabela 5

Estratégias para legitimidade moral

\begin{tabular}{|c|c|c|c|c|c|c|c|c|c|c|}
\hline & Estratégias p & Ira a Legitimação & 2010 & 2011 & 2012 & 2013 & 2014 & 2015 & 2016 & Total \\
\hline & & Produzir resultados adequados & 3 & 4 & 4 & 1 & 5 & 8 & 4 & 29 \\
\hline & Ganho & Incorporar-se a instituições & 5 & 4 & 3 & 2 & 1 & 5 & 1 & 21 \\
\hline & & Oferecer demonstrações simbólicas & 10 & 2 & 4 & 3 & 1 & 9 & 4 & 33 \\
\hline & & Definir as metas & 1 & 1 & 3 & 1 & 1 & 4 & 2 & 13 \\
\hline & & Demonstrar sucesso & 20 & 11 & 9 & 1 & 6 & 10 & 17 & 74 \\
\hline & & Fazer proselitismo & 0 & 1 & 0 & 9 & 0 & 1 & 3 & 14 \\
\hline & & Consultar as categorias profissionais & 0 & 1 & 1 & 0 & 0 & 1 & 0 & 3 \\
\hline & Manutenção & Monitorar a responsabilidade & 4 & 0 & 2 & 4 & 3 & 11 & 3 & 27 \\
\hline & & Comunicar-se oficialmente & 2 & 1 & 2 & 2 & 2 & 3 & 1 & 13 \\
\hline$\stackrel{a}{e}$ & & Estocar opiniões favoráveis & 1 & 5 & 1 & 3 & 2 & 4 & 2 & 18 \\
\hline & & Desculpar / Justificar & 0 & 5 & 8 & 0 & 1 & 11 & 4 & 29 \\
\hline & & Substituir pessoal & 1 & 1 & 0 & 1 & 0 & 0 & 1 & 4 \\
\hline & Reparação & Rever as práticas & 1 & 0 & 2 & 2 & 1 & 4 & 4 & 14 \\
\hline & & Reconfigurar & 0 & 0 & 2 & 0 & 0 & 0 & 0 & 2 \\
\hline
\end{tabular}

Fonte: elaborada pelos autores.

Pela situação resumida Tabela 5 conclui-se que a Vale tem a preocupação de demonstrar para a sociedade que segue procedimentos no sentido de "fazer a coisa certa" e que a companhia busca demonstrar o sucesso das ações que realiza, pois os resultados evidenciam que o critério ganho teve predominância em relação às estratégias de legitimidade moral. Destarte, nessa estratégia predominaram os itens "produzir resultados adequados", que são apresentados através de "demonstrações simbólicas" que visam destacar o sucesso que a empresa obteve.

Essa filosofia coaduna-se com a missão da empresa, pois "a Vale tem como missão transformar recursos naturais em prosperidade e desenvolvimento sustentável e tem como visão ser a empresa de recursos naturais global número um em criação de valor de longo prazo, com excelência, paixão pelas pessoas e pelo planeta" (RA - Vale, 2016, p. 12).

Além disso, pelo exame dos relatórios de administração da empresa em tela nota-se uma preocupação da empresa em desenvolver ações que possam resultar em efetivo ganho a todos os envolvidos, conforme relatado no trecho extraído do RA - Vale $(2010$, p. 6) onde é mencionado que

\footnotetext{
O apoio ao desenvolvimento social e econômico nas regiões onde a Vale opera é realizado através da Fundação Vale, uma das maiores fundações corporativas do mundo. A Fundação Vale estabelece parcerias com governos, organizações não governamentais e empresas privadas, promovendo iniciativas estruturantes nas áreas de infraestrutura urbana, fortalecimento da gestão pública e desenvolvimento humano e econômico. Além do Brasil, a Fundação Vale atua na Colômbia e em Moçambique.
}

Portanto, sob o prisma da legitimidade moral dessume-se que a empresa busca realizar parcerias com outras instituições e trabalha para a manutenção das suas atividades, monitora suas responsabilidades e objetiva estocar opiniões favoráveis.

Quanto à promoção da sustentabilidade, a análise dos documentos demonstrou que a empresa apresenta em todo o período de estudo o objetivo de realizar atividades que possam promover esse aspecto. Esta preocupação de realmente proporcionar valor para os envolvidos pode ser encontrada no trecho extraído do RA - Vale (2016, p. 12), onde se aduz que 
Para nós, o desenvolvimento sustentável é alcançado quando nossos negócios geram valor para nossos acionistas e demais partes interessadas, apoiando o fortalecimento social, a manutenção e melhoria da saúde e segurança de nossos trabalhadores e comunidades vizinhas, a responsabilidade ambiental e o desenvolvimento socioeconômico das regiões onde operamos, por meio de uma gestão consciente e responsável, de ações empresariais voluntárias e de parcerias intersetoriais.

Desse modo, em determinados trechos dos relatórios da administração da empresa nota-se o cuidado de seguir políticas de conduta ética e de responsabilidade social, objetivando contribuir com a sustentabilidade.

\subsection{Estratégias para legitimidade cognitiva}

$\mathrm{Na}$ legitimidade cognitiva a empresa pode receber da sociedade apoios e avaliações positivas, negativas ou neutras. A partir dessa avaliação fundamentada nas ações, atividades e envolvimentos da empresa com a sociedade é que companhia pode aquilatar seu nível de aceitação no ambiente em que está inserida (Suchman, 1995).

Acerca disso, a Tabela 6 retrata a frequência que os itens da legitimidade cognitiva foram evidenciados no relatório de administração da Vale no período de 2010 a 2016.

Tabela 6

Estratégias de legitimidade cognitiva

\begin{tabular}{c|l|l|c|c|c|c|c|c|c|c}
\hline & Estratégias para a Legitimação & $\mathbf{2 0 1 0}$ & $\mathbf{2 0 1 1}$ & $\mathbf{2 0 1 2}$ & $\mathbf{2 0 1 3}$ & $\mathbf{2 0 1 4}$ & $\mathbf{2 0 1 5}$ & $\mathbf{2 0 1 6}$ & Total \\
\hline \multirow{4}{*}{ Ganho } & Reproduzir normas & 4 & 6 & 4 & 2 & 4 & 7 & 8 & $\mathbf{3 5}$ \\
& Formalizar as operações & 4 & 8 & 6 & 7 & 4 & 3 & 10 & $\mathbf{4 2}$ \\
& Profissionalizar as operações & 4 & 8 & 5 & 3 & 3 & 3 & 8 & $\mathbf{3 4}$ \\
& Buscar certificação & 5 & 6 & 5 & 2 & 5 & 1 & 2 & $\mathbf{2 6}$ \\
& Persistir & 4 & 9 & 11 & 2 & 1 & 0 & 0 & $\mathbf{2 7}$ \\
& Popularizar novos modelos & 5 & 8 & 9 & 6 & 5 & 2 & 4 & $\mathbf{3 9}$ \\
& Padronizar novos modelos & 5 & 7 & 10 & 5 & 1 & 2 & 4 & $\mathbf{3 4}$ \\
\hline \multirow{3}{*}{ Manutenção } & Consultar aquele que tem dúvidas & 0 & 0 & 0 & 0 & 0 & 1 & 0 & $\mathbf{1}$ \\
& Visar clareza & 4 & 6 & 5 & 1 & 0 & 7 & 5 & $\mathbf{2 8}$ \\
& Falar pontualmente & 2 & 4 & 1 & 0 & 1 & 4 & 3 & $\mathbf{1 5}$ \\
& Estocar conexões & 1 & 5 & 7 & 1 & 1 & 4 & 3 & $\mathbf{2 2}$ \\
\hline
\end{tabular}

Fonte: elaborada pelos autores.

A partir da Tabela 6 verifica-se que a empresa busca o apoio positivo da sociedade, pois dos itens de legitimidade cognitiva estabelecidos destacaram-se "formalizar as operações, "popularizar novos modelos", "reproduzir normas", "padronizar novos modelos" e "profissionalizar as operações". Com esses itens em destaque a Vale mostra que prioriza desenvolver ações e projetos que possam implantar novas formas para orientar suas atividades.

Os resultados apurados equiparam-se aos de Fank e Beuren (2010), que constataram que os itens "popularizar novos modelos", "padronizar novos modelos", "reproduzir normas", "formalizar as operações", "profissionalizar as operações" e "buscar certificação" destacaramse nos relatórios de administração da empresa Petrobras no âmbito da legitimidade cognitiva.

Além desses cuidados, os achados expressos na Tabela 6 denotam que a empresa busca certificações e visa clareza nas atividades, explicando de forma pontual como suas atividades são desenvolvidas. Esses aspectos podem ser visualizados nos anos de 2010 (quando da implantação das normas internacionais da contabilidade) e em 2015 
(especialmente por ocasião da ruptura da barragem da Samarco), sendo que nestes dois anos a empresa buscou explicar os procedimentos que adotou a respeito dos dois episódios.

Esse cuidado da companhia Vale com suas atividades fica evidenciado também no RA - Vale (2011, p. 4) quando descreve que "em 2011, a Vale foi selecionada pelo segundo ano consecutivo para compor o ISE - Índice de Sustentabilidade Empresarial da BM\&F Bovespa e também continuou a fazer parte do ICO2 - Índice Carbono Eficiente". Adicionalmente, relatou que

Em 2011, a Vale foi eleita a melhor mineradora no ranking do Carbon Disclosure Project (CDP). Como consequência, fez parte pelo segundo ano consecutivo do índice Carbon Disclosure Leadership Índex (CDLI), sendo a única empresa da América Latina a constar desse índice. O CDP é uma importante instituição sem fins lucrativos, cujo objetivo é promover a redução da emissão de gases estufa e o uso sustentável da água por cidades e empresas (RA - Vale, 2011, p. 5).

Nessa direção, a empresa ressalta que para alcançar padrões de excelência em sustentabilidade "desenvolve uma série de ações norteadas por políticas globais, tais como a Política de Desenvolvimento Sustentável, a Política de Direitos Humanos e a Política de Saúde e Segurança" (RA - Vale, 2011, p. 5).

Com isso, visualiza-se nos relatórios de administração da empresa o cuidado em desenvolver ações e projetos que possam implantar novas formas para orientar suas atividades e buscar certificações, visando clareza nas atividades e explicando de forma pontual como suas atividades são desenvolvidas.

\subsection{Comparação da frequência de evidenciação dos critérios e das estratégias}

Após realizada a análise de cada estratégia de legitimidade nos moldes do proposto por Suchman (1995) buscou-se analisar a predominância dos critérios "ganho", "manutenção" e "reparação" no período de 2010 a 2016, considerando as legitimidades geral, pragmática, moral e cognitiva. Com isso, almejou-se identificar quais critérios apresentaram maiores quantidades de menções dos itens analisados, cuja frequência está deslindada de forma sumarizada na Tabela 7.

Tabela 7

Frequência de evidenciação dos critérios nas estratégias de legitimidade

\begin{tabular}{l|c|c|c|c|c|c|c|c}
\hline Critérios & $\mathbf{2 0 1 0}$ & $\mathbf{2 0 1 1}$ & $\mathbf{2 0 1 2}$ & $\mathbf{2 0 1 3}$ & $\mathbf{2 0 1 4}$ & $\mathbf{2 0 1 5}$ & $\mathbf{2 0 1 6}$ & Total \\
\hline Ganho & 173 & 168 & 110 & 69 & 61 & 134 & 136 & $\mathbf{8 5 1}$ \\
Manutenção & 132 & 122 & 59 & 44 & 32 & 100 & 55 & $\mathbf{5 4 4}$ \\
Reparação & 40 & 47 & 39 & 18 & 15 & 67 & 25 & $\mathbf{2 5 2}$ \\
\hline Total de itens & $\mathbf{3 4 5}$ & $\mathbf{3 3 7}$ & $\mathbf{2 0 8}$ & $\mathbf{1 3 1}$ & $\mathbf{1 0 8}$ & $\mathbf{3 0 1}$ & $\mathbf{2 1 6}$ & $\mathbf{1 6 4 6}$ \\
\hline
\end{tabular}

Fonte: elaborada pelos autores.

Considerando os dados da Tabela 7 percebe-se que o critério "ganho" apresentou maior quantidade de itens identificados nos relatórios de administração da companhia pesquisada no período de 2010 a 2016, com um total de 851 citações. Assim, conforme apresentado nas tabelas anteriores, despontaram os itens vinculados a adaptar-se ao ambiente, objetivando responder as necessidades, produzindo resultados adequados, pautando-se nas normas, com profissionalização e padronização das operações e modelos, almejando demonstrar sucesso construindo imagem e reputação favoráveis para receber da sociedade uma avaliação positiva. 
Quanto ao total de itens identificados, constatou-se que no período analisado estes chegaram 1.646 menções, com destaque para o critério "ganho" (com 51,70\% do total), onde o ano 2010 foi o que apresentou a maior quantidade de itens (com 346 menções) e 2014 foi o ano com menor número total de itens identificados (somente 108).

A Tabela 8 demonstra a frequência de evidenciação das estratégias de legitimidade geral, pragmática, moral e cognitiva nos sete anos pesquisados.

Tabela 8

Resumo das estratégias de legitimidade geral, pragmática, moral e cognitiva

\begin{tabular}{l|c|c|c|c|c|c|c|c}
\hline Estratégias de legitimidade & $\mathbf{2 0 1 0}$ & $\mathbf{2 0 1 1}$ & $\mathbf{2 0 1 2}$ & $\mathbf{2 0 1 3}$ & $\mathbf{2 0 1 4}$ & $\mathbf{2 0 1 5}$ & $\mathbf{2 0 1 6}$ & Total \\
\hline Geral & 124 & 132 & 49 & 38 & 24 & 91 & 43 & $\mathbf{5 0 1}$ \\
Pragmática & 102 & 81 & 34 & 22 & 25 & 71 & 71 & $\mathbf{4 0 5}$ \\
Moral & 48 & 36 & 41 & 29 & 23 & 71 & 46 & $\mathbf{2 9 4}$ \\
Cognitiva & 72 & 88 & 84 & 42 & 36 & 68 & 56 & $\mathbf{4 4 6}$ \\
\hline
\end{tabular}

Fonte: elaborada pelos autores.

Considerando as estratégias de legitimidade geral, pragmática, moral e cognitiva propostas por Suchman (1995), percebe-se na Tabela 8 que nos relatórios de administração da companhia de mineração Vale S. A., no período de 2010 a 2016, predominou a legitimidade geral com 501 citações. Esse número equivale a 30,44\% do total de 1.646 citações e foi seguido pela legitimidade cognitiva (que contou com 446 menções), pela legitimidade pragmática (para a qual foram identificados 405 relatos) e pela legitimidade moral (com apenas 294 itens identificados).

Por esse ângulo de análise, os resultados desta pesquisa diferem os encontrados por Fank e Beuren (2010), de vez que identificaram nos relatórios de administração da Petrobras a predominância da legitimidade cognitiva. Da mesma forma, diferem do estudo de Farias et al., (2014) que objetivou identificar as estratégias de legitimidade da tipologia de Suchman (1995) evidenciadas pela empresa Brasken, onde predominou a tipologia pragmática, com metade das evidenciações.

Suarez, Román e Román (2013) estudaram seis universidades públicas espanholas com o fito de medir a relação entre a legitimidade cognitiva, acesso aos recursos e resultados organizacionais. Os resultados obtidos apoiam a afirmação de que as organizações com maior legitimidade cognitiva possuem maior acesso aos recursos e, portanto, melhoraram os seus resultados. Contudo, no caso da Vale S. A. os itens que receberam mais citações indicam que esta companhia está se adaptando ao ambiente, sendo capaz de perceber as mudanças e de monitorar as operações para, a partir disso, comunicar-se habilmente para "estocar" legitimidade.

\section{CONSIDERAÇÕES FINAIS}

O estudo teve como objetivo identificar as estratégias de legitimidade da tipologia de Suchman (1995) que a companhia de mineração Vale S. A. evidenciou nos seus relatórios da administração no período de 2010 a 2016.

Os autores consideram que tal objetivo foi atingido porque foram identificados os resultados mencionados nas seções precedentes em termos de legitimidade geral e de legitimidade cognitiva mais presentes no relatório de administração da empresa em lume.

Nesse rumo, em relação à legitimidade geral concluiu-se que predominou o critério "manutenção", onde foram identificadas mais citações dos itens que demonstram que entidade está percebendo as mudanças no cenário, monitorando as suas operações e, a partir disso, comunica-se habilmente no sentido de angariar mais legitimidade. 
Dos itens de "manutenção" propostos por Suchmann (1995), "estocar legitimidade" destacou-se na análise dos relatórios da administração, seguido de "comunicar-se habilmente". Além disso, dos sete períodos analisados, percebeu-se que em 2010 houve maior quantidade de vezes que os itens foram detectados nos relatórios examinados. Tal fato provavelmente advém de que nesse ano tornou-se obrigatório para as empresas com capital aberto a implantação das normas internacionais de contabilidade (IFRS) e a empresa descreveu detalhadamente como realizou esse processo de adaptação.

No âmbito da legitimidade pragmática dessumiu-se que predominou o critério "ganho" pois restou evidente que a empresa busca a percepção da sociedade sobre ela. Dos itens avaliados, predominaram "construir reputação" e" anunciar a imagem" com 97 e 94 evidenciações, respectivamente. Ainda em relação à predominância do ganho, a empresa busca responder as necessidades da sociedade e dos seus acionistas, objetivando que todas as partes possam ser cooperadores amistosos e com isso a sua imagem seja mais positiva.

Quanto à legitimidade moral, considerando-se os itens com mais citações, os resultados demonstraram que a companhia tem a preocupação de deixar claro para a sociedade que segue os procedimentos recomendados e busca demonstrar sucesso nas ações que executa. Isso é corroborado pelo fato de que o critério ganho predominou em relação às estratégias de legitimidade moral. Ainda, em relação a esse parâmetro, foram mais frequentes os itens que sinalizam que a empresa busca produzir resultados adequados, que são apresentados através de demonstrações simbólicas, objetivando demonstrar sucesso no que efetivamente realiza. Essa filosofia se alia à missão da empresa, que é de transformar recursos naturais em prosperidade e desenvolvimento sustentável. Portanto, os resultados quanto à legitimidade moral também apontam que a organização preocupa-se em desenvolver ações que possam resultar em efetivo ganho a todos os envolvidos, buscando realizar parcerias com outras instituições e promovendo a sustentabilidade.

No que tange aos resultados da análise de conteúdo dos relatórios de administração, estes mostraram predominância dos itens que visam formalizar as operações, popularizar novos modelos, reproduzir normas, padronizar novos modelos e profissionalizar as operações em relação à legitimidade cognitiva. Permitem considerar também que a empresa busca certificações e visa clareza nas atividades, explicando de forma pontual como suas atividades são desenvolvidas.

De forma geral, em relação aos critérios analisados (ganho, manutenção e reparação), os achados apontam que o critério "ganho" apresentou maior quantidade de itens identificados nos relatórios de administração da companhia nos sete anos. Por outro lado, ao se considerar as estratégias de legitimidade geral, pragmática, moral e cognitiva, os resultados demonstram que a estratégia geral foi a mais citada, seguida pela cognitiva, pragmática e moral, respectivamente.

Quanto às possíveis contribuições do estudo, considera-se que o aspecto mais relevante está ligado ao comparativo efetuado entre estudos realizados em outras empresas, ocorrendo a possibilidade de comparações nas formas de conduta de suas atividades. No âmbito nacional foi comparado com os estudos de Fank e Beuren (2010) e de Farias et al. (2014), que objetivaram identificar as estratégias de legitimidade da tipologia de Suchman (1995) evidenciadas pelas empresas Petrobras e Brasken, respectivamente. No âmbito internacional, fez-se a comparação com o estudo realizado por Suarez, Román e Román (2013), que investigaram a realidade de seis universidades públicas espanholas.

Quanto às limitações do estudo, é interessante mencionar que para o desenvolvimento deste, focou-se exclusivamente num caso, não devendo dessa forma os resultados serem generalizados, restringindo-se à empresa e aos períodos analisados. Outro fato a ser 
considerado é a subjetividade na análise de conteúdo, com interpretações pessoais por parte do pesquisador que podem afetar as conclusões a respeito.

Para futuras pesquisas recomenda-se realizar o estudo em outras empresas, tanto do mesmo setor, quanto de setores de atuação diferentes, proporcionado comparar os resultados com os achados ora relatados.

\section{REFERÊNCIAS}

Akerlof, R. (2017). The Importance of legitimacy. World Bank Economic Review, v. 30, Issue Supplement1, n. 1, p. S157-S165.

Bardin, L. (1977). Análise de conteúdo. Lisboa: Edições 70.

Beuren, I. M, Hein, N., \& Boff, M. L. (2011). Estratégias de legitimidade organizacional de Lindblom versus geração familiar gestora de empresas familiares. $R I G C$, v. 9, n. 17, p. 120.

Boff, M. L. (2007. Estratégias de legitimidade organizacional de Lindblom na evidenciação ambiental e social em relatórios da administração de empresas familiares. 2007. $160 \mathrm{f}$. Dissertação (Mestrado em Ciências Contábeis) - Programa de Pós-Graduação em Ciências Contábeis da Universidade Regional de Blumenau, Blumenau.

Casagrande, R. M., \& Lavarda C. E. F. (2015). Convergências teóricas entre a governança corporativa e a sustentabilidade sob a perspectiva da legitimidade. Revista de Gestão Social e Ambiental - RGSA, São Paulo, v. 9, n. 2, p. 88-101.

Coronel, D. A., Lago, A., Lengler, L., \& Silva, T. N. (2007) O aproveitamento dos resíduos do setor florestal de Lages - Santa Catarina. In: CONGRESSO DA SOCIEDADE BRASILEIRA DE ECONOMIA, ADMINISTRAÇÃO E SOCIOLOGIA RURAL, 14, 2007, Londrina. Anais... Londrina/PR.

Deephouse, D. L., \& Carter, S. M. (2005). An examination of differences between organizational legitimacy and organizational reputation. Journal of Management Studies, v. 42 , n. 2, p. 329-360.

Deephouse, D. L., \& Suchman, M. (2008). Legitimacy in organizational institutionalism. In: The Sage handbook of organizational institutionalism. Sage Publications, p.49-77.

Dias Filho, J. M. (2007). Políticas de evidenciação contábil: um estudo do poder preditivo e explicativo da teoria da legitimação. In: EnANPAD, 31., 2007, Rio de Janeiro. Anais... Rio de Janeiro: ANPAD.

Fank, O. L., \& Beuren, I. M. (2010). Evidenciação das estratégias de legitimidade da tipologia de Suchman (1995) nos relatórios da administração da Petrobras. RCO - Revista de Contabilidade e Organizações - FEA-RP/USP, v. 4, n. 10, p. 25-47.

Farias, L. G. Q., Andrade, J. C. S., Góes, M. F. B., \& Rabelo Filho, R. L. N. (2014). Estratégias de legitimidade como resposta ao problema das mudanças climáticas: o caso BRASKEM. REUNA, Belo Horizonte - MG, Brasil, v.19, n.2, p.135 - 152.

Fisher, G., Kotha S., \& Lahiri, A. (2016). Changing with the times: an integrated view of identity, legitimacy and new venture life cycles. Academy of Management Review, v. 41, n. 3 p. 383-409.

Gil, A. C. (1999). Métodos e técnicas de pesquisa social. $5^{\text {a }}$ ed. São Paulo: Atlas.

Gubiani, C. A., Soares, M., \& Beuren, I. M. (2009). Estratégias de legitimidade de Suchman evidenciadas nos relatórios da administração de empresas públicas do setor elétrico. In: EnANPAD, 33. 2009, São Paulo. Anais ... Rio de Janeiro: ANPAD.

Lindblom, C. K. (1994). The implications of organizational legitimacy for corporate social performance and disclosure. Critical Perspectives on Accounting. In: Critical Perspectives on Accounting Conference. New York. 
Lunkes, R. J., Schnorrenberger, D., Souza, C. M., \& Rosa, F. S. (2012). Análise da legitimidade sociopolítica e cognitiva da controladoria no Brasil. Revista de Contabilidade \& Finanças [online], v. 23, n.59, p. 83-101.

Lunkes, R. J., Ferreira, L.F., Rech, J. de O., \& Renzzieri, T. (2014). A Legitimidade cognitiva da disciplina de planejamento tributário no Brasil. Contabilidade, Gestão e Governança, v. 17, n. 2 , p. $45-59$.

O'Donovan, G. (2002). Environmental disclosures in annual report: extending the applicability and predictive power of legitimacy theory. Accounting, Auditing \& Accountability Journal, v. 15, n. 3. p. 344-371.

Palazzo, G., \& Scherer, A. G. (2006). Corporate legitimacy as deliberation: a communicative framework. Journal of Business Ethics, v. 66, n. 1.

Parente, C., Barbosa, G. M., \& Gomes, M. (2016). A comunicação externa como veículo de legitimidade organizacional no terceiro setor. Ciem2016 - $6^{\mathrm{a}}$ Conferência Ibérica de Empreendedorismo. 27 e 28 de out. de 2016, Rectorado de la Universidade da Coruña. Anais... Portugal.

Parsons, T. (1956). Suggestions for a sociological approach to the theory of organizations-I. Administrative Science Quarterly, v. 1, n. 1, p. 63-85.

Pfeffer, J., \& Salancik, G. R. (1978). The external control of organizations: a resource dependence perspective. New York: Harper \& Row.

Richardson, R. J. (1989). Pesquisa social: métodos e técnicas. 2a ed. São Paulo: Atlas.

Rosa, F. S., \& Lunkes, R. J. (2005). Revolução verde: a gestão ambiental auxiliando a transformar o fantasma da poluição ineficiente em vantagem competitiva. In: CONGRESSO INTERNACIONAL DE CUSTOS, 2005, Florianópolis. Anais... Itapema/SC.

Sancovschi, M., \& Silva, A. H. C. e. (2006). Evidenciação social corporativa: estudo de caso da empresa Petróleo Brasileiro S. A. Sociedade, Contabilidade e Gestão, v. 1, n. 1, p. $42-$ 57.

Scott, W. R. (2001). Institutions and organizations. $2^{\mathrm{a}}$ ed. London: Sage Publications, 2001.

Silva, A. C. R. (2003). Metodologia da pesquisa aplicada à contabilidade: orientações de estudos, projetos, relatórios, monografias, dissertações, teses. São Paulo: Atlas.

Steffek, J. (2009). Discursive legitimation in environmental governance. Forest Policy and Economics, v. 11, n.5-6, p. 313-318.

Suarez, A. C., Román, A. P., \& Román, M. P. (2014). Cognitive legitimacy, resource access, and organizational outcomes. RAE - Revista de Administração de Empresas. São Paulo, v. 54 , n. 5 , p. 575-584.

Suchman, M. (1995). Managing legitimacy: strategic and institutional approaches. Academy of Management Review. v. 20, n. 3, p. 571-610.

Vale S.A. (2017). Sobre a Vale. Disponível em: $<$ http://www.vale.com/brasil/PT/aboutvale/mission/Paginas/default.aspx $>$ Acesso em: 30 set. 2017.

Vilela Júnior, A., \& Demajorovic, J. (2006). Modelos e ferramentas de gestão ambiental: desafios e perspectivas para as organizações. São Paulo: Ed. SENAC.

Watts, R. L., \& Zimmerman, J. L. (1990). Positive accounting theory: a ten years perspective. The Accounting Review, v. 65, n. 1. p. 131-156. 